\title{
Bacteriuria and Antimicrobial Susceptibility Pattern Among HIV Patients Attending ALERT Center, Addis Ababa, Ethiopia
}

\author{
Yemisrach Getu ${ }^{1}$, Ibrahim Ali ${ }^{2}$, Tsehaynesh Lema ${ }^{3}$, Habtamu Belay ${ }^{4,}$, Biruk Yeshetela ${ }^{3}$ \\ ${ }^{1}$ All Africa Leprosy, Tuberculosis and Rehabilitation Training (ALERT) Center, Addis Ababa, Ethiopia \\ ${ }^{2}$ Department of Clinical Laboratory Sciences, School of Allied Health Sciences, Addis Ababa University, Addis Ababa, Ethiopia \\ ${ }^{3}$ Department of Bacteriology, Virology and Mycology, Armauer Hansen Research Institute (AHRI), Addis Ababa, Ethiopia \\ ${ }^{4}$ Department of Microbiology, LABCO Advanced Clinical Laboratory, Addis Ababa, Ethiopia
}

Email address:

birutgetu@gmail.com (Y. Getu), abrarawibrahim@gmail.com (I. Ali),rbpt21@yahoo.com (T. Lema), hbtmbelay652@gmail.com (H. Belay),biruk_23@yahoo.com (B. Yeshetela)

${ }^{*}$ Corresponding author

\section{To cite this article:}

Yemisrach Getu, Ibrahim Ali, Tsehaynesh Lema, Habtamu Belay, Biruk Yeshetela. Bacteriuria and Antimicrobial Susceptibility Pattern Among HIV Patients Attending ALERT Center, Addis Ababa, Ethiopia. American Journal of Health Research.

Vol. 5, No. 3, 2017, pp. 76-82. doi: 10.11648/j.ajhr.20170503.14

Received: March 16, 2017; Accepted: March 30, 2017; Published: May 16, 2017

\begin{abstract}
Urinary tract infections are some of the most common bacterial diseases both in general population and amongst HIV infected patients. It is important to define the prevalence and drug susceptibility pattern of bacteriuria among HIV patients in Ethiopia and especially in Addis Ababa, because of the information scarcity about bacteriuria in HIV patients in our region. A cross sectional study was conducted in ALERT Center; Addis Ababa, Ethiopia; from 2014 to 2015 among 165 adult HIV patients. Midstream urine was collected with sterile wide-mouthed urine cups. Samples were inoculated to Cysteine lactose electrolyte deficient, Blood agar and MacConkey accordingly and biochemical tests performed to identify the isolates. Drug susceptibility pattern of isolates were determined using the disk diffusion techniques. Data analyzed using SPSS version-20 software package. Chi-square test was used to see the association between the outcome variable and independent and the strength of the association was identified using odds ratio in the binary logistic regression. Female study participants showed at least three times more likely to have bacteriuria $(\mathrm{AOR}=3.25,95 \% \mathrm{CI}=0.98-10.79)$ than the male. Subsequent multivariate analysis CD4 value less than 200 cells $/ \mathrm{mm} 3(\mathrm{p}=0.02)$ retained its significance association. Presence of dysuria was almost three times $(\mathrm{AOR}=2.87 ; 95 \% \mathrm{CI}=0.84-9.79)$ and previous history of UTI at least two times $(\mathrm{AOR}=2.38 ; 95 \%=0.73-7.72)$ more likely to have bacteriuria than absence of them. The isolated bacteria were E. coli (38.5\%), followed by $S$. aureus $(30.8 \%), P$. mirabilis (11.5\%), S. epidermidis (11.5\%) and S. saprophyticus $(7.7 \%)$. Bacterial isolates in the current study were most sensitive to ceftriaxone (100\%), nitrofurantoin $(88.46 \%)$, gentamicin $(84.62 \%)$ and ceftazidime $(84.62 \%)$ while resistant to ampicillin $(84.62 \%)$, tetracycline $(92.31 \%)$ and trimethoprim-sulfamethoxazole $(88.46 \%)$. The occurrence of bacteriuria and susceptibility pattern of the antibiotics in the current study was comparable to other studies in HIV patients. The identified bacteria were reported by other authors as UTI causative agents in HIV patients. Still, bacteriuria in HIV patients needs more consideration for better management and preventing drug resistance.
\end{abstract}

Keywords: Urinary-Tract Infection, HIV/AIDS, Bacteriuria, Antimicrobial-Susceptibility Pattern

\section{Introduction}

Urinary tract infections (UTI) are some of the most common bacterial diseases [1]. This may lead to increasing mortality rate, disability, hospitalization and economic costs next to respiratory infections [2]. Additionally, UTI's at first presenting as urologic abnormalities may also lead to renal failure and hypertension [3]. Dysuria, frequency, urgency, and suprapubic tenderness are some of the symptoms of UTI 
[4].

This is known to be one of the opportunistic infection [5, 6] which, accounts for $60.0 \%$ the AIDS defining illness [7]. Therefore, UTI represents a considerable health problem amongst HIV infected patients [5, 7]. This Bacterial infections are a common cause of morbidity and mortality in HIV positive individuals [8, 9]. In HIV-positive patients, UTI tends to recur, requiring longer treatment and it is suggested that treatment should be culture-specific [7]. Due to the growing number of emerging uropathogens and the simultaneous increase of newer antibiotics, it is mandatory that laboratories use standardized methods and report only appropriate antibiotics for UTI [1].

There is, however, limited data on UTI of HIV/AIDS patients, in developing countries like Ethiopia in general Addis Ababa region in particular. This study is the first report that directly relates HIV with uropathogens in Addis Ababa region and it can provide updated information as well. We strongly believe that this study will be additional input to strength the management of HIV patients related to treatment and prevention of urinary tract infections. The aim of the current study was to determine the prevalence and drug susceptibility pattern of bacterial associated UTI among HIV positive patients attending ALERT Center.

\section{Methods}

\subsection{Study Area and Population}

The study was carried out at the department of microbiology laboratory of ALERT center, Addis Ababa, Ethiopia from September 2014 to January 2015. ALERT center is one of the largest referral and training center that provide services mainly in Dermatology and ART treatment for patients throughout the country. All HIV positive individual who are attending ALERT Center during the study period were considered as study population. Patients who were able to give consent to participate in the study and greater than 18 were included. While patients who are on antibiotics for the last two weeks of enrolment were not included.

\subsection{Sample Size Determination and Sampling Technique}

The required sample size was determined by using single population formula considering the following assumptions: Prevalence $\sim 11 \%$ (prevalence of culture proven HIV UTI patients that was previously done in Ethiopia [10]), level of significance $=0.05$ with marginal of error $(d)=5 \%$, and Nonresponse rate $=10 \%$. The overall sample size was found to be 165 individuals. All consecutive HIV patients were included in this study by convenient technique.

\subsection{Data and Specimen Collection}

Physicians and professional nurses from ART clinic with relevant experience were recruited and trained for two days on the method of the data collection. The training addressed issues such as the content and completing of the questionnaire and how to collect mid-stream urine sample. The written consent was obtained from the study participants by professional Nurses. Relevant information including; age, sex, symptoms, were gathered using a prepared questionnaires. Laboratory data, urine culture and sensitivity results were also recorded.

The participants' current CD4 value was taken from their medical records upon which urine sample and other relevant data were collected. The urine sample collections were performed as described elsewhere $[2,10,11]$.

\subsection{Processing Urine Sample}

Using calibrated loop designed to deliver $0.001 \mathrm{ml}$ of well mixed un-centrifuged urine was inoculated on to Cysteine Lactose Electrolyte Deficient (CLED) medium. After 24-48 hours of incubation at $35 \mathrm{C}-37 \mathrm{C}$ aerobically, the plates were examined for the presence of colonies. Isolates were considered significant, if there were $\geq 10^{5}$ colony forming unit $/ \mathrm{mL}(\mathrm{CFU} / \mathrm{mL})$ of urine as stated elsewhere [11-13]. Then the suspected colonies were sub-cultured to $5 \%$ sheep blood agar and MacConkey agar plates. Significant isolates were selected for identification.

\subsection{Bacterial Identification}

Further isolation and identification of colonies were done according to standard microbiological procedures. Such as; hemolytic reaction, pigment production or color changes surrounding carbohydrate fermenting colonies, colony characteristic and gram reaction were presumptive identification. Gram negative bacteria were identified using a series of biochemical tests; included fermentation of dextrose, lactose, sucrose, production of hydrogen sulfide, citrate utilization, lysine decarboxylase, urea hydrolysis, motility, and indole tests. Whereas, catalase, coagulase, mannitol fermentation, DNase, Novobiocin (NOV, $5 \mu \mathrm{g}$ ) antibiotic disk were used for the identification of gram positive bacteria as described by others $[14,15]$.

\subsection{Antimicrobial Susceptibility Testing (AST)}

The isolates were performed Modified Kirby Bauer disc diffusion test according to the Clinical and Laboratory Standard Institute [16]. Briefly, a pure culture 3-5 selected colonies of bacteria was taken and transferred to a tube containing $5 \mathrm{ml}$ sterile normal saline and mixed gently to make homogenous suspension and the turbidity of the suspension was adjusted to a McFarland 0.5 standard. A sterile cotton swab was used to streak the plates and the excess suspension was removed by gentle pressing and rotation of the swab against the inside wall surface of the tube. The swab was then used to distribute the bacteria evenly over the entire surface of Mueller Hinton agar (MHA). The inoculated plates were left at room temperature to dry for 3-5 minutes and a set of antibiotic discs were impregnated on the MHA as described by CLSI [16].

The following antibiotic disks were used; ampicillin $(10 \mu \mathrm{g})$, amoxicillin-clavulanic acid $(10 \mu \mathrm{g})$, ceftazidime 
(30 $\mu \mathrm{g}), \quad$ ceftriaxone $(10 \mu \mathrm{g}), \quad$ ciprofloxacin $\quad(5 \mu \mathrm{g})$, trimethoprim-sulfamethoxazole $\quad(25 \mu \mathrm{g}), \quad$ erythromycin $(15 \mu \mathrm{g})$, gentamicin $(10 \mu \mathrm{g})$, nitrofurantoin $(300 \mu \mathrm{g})$, norfloxacin $(10 \mu \mathrm{g})$, tetracycline $(30 \mu \mathrm{g})$ and penicillin $(10 \mu \mathrm{g})$. The plates were incubated in aerobic atmosphere at $37 \mathrm{C}$ for 16-18 hours. Diameters of the zone of inhibition around the disc was measured to the nearest whole mm using a graduated caliper [16].

\subsection{Quality Control}

Culture media were tested for sterility and performance. Standard strains of E. coli ATCC 25922 and S. aureus ATCC 25923 were used during culture and antimicrobial susceptibility testing.

\subsection{Statistical Analyses}

The clinical and laboratory data collected from each study subject was recorded on a standard registration format. After the data was checked for its completeness it was analyzed using SPSS version-20 software package for descriptive and inferential analyses. The results are presented in percentages, figures and graphs where appropriate. Binary logistic regression was employed to examine the associations between the outcome variables (presence or absence of significant bacteriuria) with the various independent factors (socio-demographic and clinical features), and the results are presented using odds ratios (ORs) and confidence intervals (95\% CI).

To ascertain the association between the dependent variables and the explanatory variables, simultaneously controlling for the aforementioned explanatory variables, (All socio-demographic characteristics and other covariates associated in univariate with $\mathrm{p}<0.2$ were used and entered) stepwise logistic regression was applied and adjusted odds ratios (AORs) and confidence intervals (95\% CI) were constituted. In all analyses, $\mathrm{P}<0.05$ was considered to be statistically significant.

\subsection{Ethical Considerations}

Ethical clearance was obtained from the Department of Clinical Laboratory Science; Addis Ababa University; and a letter of support was written to ALERT Center. Official permission was also obtained from ALERT Ethics Review Committee. All study records that identify subjects were kept confidential. The objectives of the study were explained to the study participants and informed consent was obtained before interviewing each participant. All the information obtained from the study participants was kept confidential, names or personal identifiers were not included and identification of each participant was only possible through numerical codes.

\section{Results}

The sociodemographic characteristics of the 165 HIV patients who participated in our study are summarized in
Table 1. Most of our participants (69.1\%) were female, age category 28-37 years (43.0\%), had accomplished primary school (56.4\%), unmarried (58.2\%) and Addis Ababa city dwellers $(90.9 \%)$.

Table 1. Socio-demographic characteristics of HIV positive patients attending ALERT Center, Addis Ababa, Ethiopia, 2015 ( $n=165)$.

\begin{tabular}{llll}
\hline Characteristics & Category & Frequency & Percent \\
\hline \multirow{4}{*}{ Age (years) } & $18-27$ & 14 & 8.5 \\
& $28-37$ & 71 & 43.0 \\
& $38-47$ & 58 & 35.2 \\
Sex & $48-57$ & 13 & 7.9 \\
& $\geq 58$ & 9 & 5.5 \\
Residence & Male & 51 & 30.9 \\
& Female & 114 & 69.1 \\
Marital status & Addis Ababa & 150 & 90.9 \\
& Out of Addis Ababa & 15 & 9.1 \\
& Married & 69 & 41.8 \\
Level of education & Unmarried & 96 & 58.2 \\
& Illiterate & 25 & 15.2 \\
& Primary School & 93 & 56.4 \\
& Secondary school & 37 & 22.4 \\
Occupation & University & 10 & 6.1 \\
& Government worker & 28 & 17.0 \\
& Private employee & 88 & 53.3 \\
& House wife & 49 & 29.7 \\
\hline
\end{tabular}

Out of the study participants $6.1 \%(10 / 165)$ were known diabetic patients, $4.8 \%(8 / 165)$ and $12.7 \%$ (21/165) had previously catheterized and history of UTI respectively. On the other hand $42.4 \%(70 / 165)$ of the study participants categorized as UTI symptomatic whereas $57.6 \%(95 / 165)$ belonged to UTI asymptomatic (Table 2).

Table 2. Frequency of clinical characteristics of HIV positive patients attending ALERT Center; Addis Ababa, Ethiopia; 2015 ( $n=165)$.

\begin{tabular}{lll}
\hline \multirow{2}{*}{ Clinical conditions } & \multicolumn{2}{l}{ Response of study subjects } \\
\cline { 2 - 3 } & $\begin{array}{l}\text { Present Frequency } \\
(\%)\end{array}$ & $\begin{array}{l}\text { Absent Frequency } \\
(\%)\end{array}$ \\
\hline Fever & $47(28.5)$ & $118(71.5)$ \\
Dysuria & $47(28.5)$ & $118(71.5)$ \\
Frequency of Urination & $62(37.6)$ & $103(62.4)$ \\
Urgency & $41(24.8)$ & $124(75.2)$ \\
History of diabetic & $10(6.1)$ & $156(93.9)$ \\
History of Catheterization & $8(4.8)$ & $158(95.2)$ \\
History of UTI & $21(12.7)$ & $144(87.3)$ \\
Symptoms of UTI & $70(42.4)$ & $95(57.6)$ \\
\hline
\end{tabular}

Of the 165 samples, significant bacteria were isolated from 26 samples giving the overall prevalence of $15.75 \%$. The association between study variables and bacteriuria in HIV patients at ALERT center are depicted in table 3 and 4.

Among the socio-demographic characteristics and the main outcome of the current study showed no statistically significance relation. However, female study participants showed at least three times more likely to have significant bacteriuria $(\mathrm{AOR}=3.25, \quad 95 \% \quad \mathrm{CI}=0.98-10.79)$ when compared to male study participants. On the other hand being housewife $(\mathrm{OR}=1.95,95 \% \mathrm{CI}=0.56-6.74)$ tend to be more likely affected than government employee respondents (Table 3). 
Table 3. Univariate and multivariate analysis for predictors of sociodemographic variables towards bacteriuria in HIV patients in ALERT center; Addis Ababa, Ethiopia, 2015.

\begin{tabular}{|c|c|c|c|c|c|}
\hline \multirow{2}{*}{\multicolumn{2}{|c|}{ Characteristics }} & \multicolumn{2}{|c|}{ Urine Culture Result } & \multirow{2}{*}{ COR $(95 \%$ CI $)$} & \multirow{2}{*}{$\operatorname{AOR}(95 \% \mathrm{CI})$} \\
\hline & & Positive n (\%) & Negative n (\%) & & \\
\hline \multirow{5}{*}{ Age (Years) } & $18-27$ & $3(21.4)$ & $11(78.6)$ & 1 & \\
\hline & $28-37$ & $11(15.5)$ & $60(84.5)$ & $0.67(0.16-2.81)$ & \\
\hline & $38-47$ & $10(17.2)$ & $48(82.8)$ & $0.76(0.18-3.25)$ & \\
\hline & $48-57$ & $1(7.7)$ & $12(92.3)$ & $0.31(0.03-3.39)$ & \\
\hline & $>58$ & $1(11.1)$ & $8(88.9)$ & $0.46(0.04-5.26)$ & \\
\hline \multirow{2}{*}{ Sex } & Male & $4(7.8)$ & $47(92.2)$ & 1 & 1 \\
\hline & Female & $22(19.3)$ & $92(80.7)$ & $2.81(0.92-8.63)^{* *}$ & $3.25(0.98-10.79)$ \\
\hline \multirow{2}{*}{ Address } & AA & $25(16.7)$ & $125(83.3)$ & 1 & \\
\hline & Out & $1(6.7)$ & $14(93.3)$ & $0.34(0.05-2.84)$ & \\
\hline \multirow{3}{*}{ Marital } & Married & $12(17.4)$ & $57(82.6)$ & 1 & \\
\hline & Unmarried & $14(14.6)$ & $82(85.4)$ & $0.81(0.35-1.88)$ & \\
\hline & Government worker & $4(14.3)$ & $24(85.7)$ & 1 & \\
\hline \multirow[t]{2}{*}{ Occupation } & Private & $10(11.4)$ & 78 (88.6) & $0.77(0.22-2.68)$ & \\
\hline & Housewife & $12(24.5)$ & $37(75.5)$ & $1.95(0.56-6.74)$ & \\
\hline \multirow{4}{*}{ Education } & Illiterate & $4(16.0)$ & $21(84.0)$ & 1 & \\
\hline & Element & $14(15.0)$ & $79(85.0)$ & $0.93(0.28-3.12)$ & \\
\hline & High school & $7(18.9)$ & $30(81.1)$ & $1.23(0.32-4.72)$ & \\
\hline & University & $1(10.0)$ & $9(90.0)$ & $0.58(0.06-5.97)$ & \\
\hline
\end{tabular}

Where; **p-value $<0.2$.

Indeed, the association between the clinical features and the growth of bacteria in their urine were measured. Only dysuria $(\mathrm{p}=0.03)$ and $\mathrm{CD} 4$ value less than 200 cells $/ \mathrm{mm} 3$ $(p=0.03)$ were found to be crudely significantly associated with growth of bacteriuria. Following multivariate analysis CD4 value less than 200 cells $/ \mathrm{mm} 3(\mathrm{p}=0.02)$ retained its significance association. Nevertheless, presence of dysuria was almost three times ( $\mathrm{AOR}=2.87 ; 95 \% \mathrm{CI}=0.84-9.79)$ and who had previous history of UTI at least two times
$(\mathrm{AOR}=2.38 ; 95 \%=0.73-7.72)$ more likely to have bacteriuria as compared to absence of them. Moreover, who had previous history of catheterization almost two times $(\mathrm{COR}=1.85 ; 95 \% \mathrm{CI}=0.35-9.70)$ and UTI symptomatic respondents at least once $(\mathrm{COR}=1.44 ; 95 \% \mathrm{CI}=0.62-3.33)$ tended to be more likely to develop bacteriuria than the respondents who had not previously catheterized and UTI asymptomatic study subjects of the current study (Table 4).

Table 4. Univariate and multivariate for predictors of clinical characteristics towards bacteriuria in HIV patients in ALERT center; Addis Ababa Ethiopia, $2015(n=165)$.

\begin{tabular}{|c|c|c|c|c|c|}
\hline \multirow{2}{*}{ Characteristics } & & \multicolumn{2}{|c|}{ Urine Culture Result } & \multirow{2}{*}{ COR $(95 \%$ CI) } & \multirow{2}{*}{$\operatorname{AOR}(95 \% \mathrm{CI})$} \\
\hline & & Positive n (\%) & Negative n (\%) & & \\
\hline \multirow{2}{*}{ Fever } & No & $18(15.3)$ & $100(84.7)$ & 1 & \\
\hline & Yes & $8(17.0)$ & $39(83.0)$ & $1.14(0.46-2.84)$ & \\
\hline \multirow{2}{*}{ Dysuria } & No & $14(11.9)$ & $104(88.1)$ & 1 & 1 \\
\hline & yes & $12(25.5)$ & $35(74.5)$ & $2.55(1.08-6.02)^{*}$ & $2.87(0.84-9.79)$ \\
\hline \multirow{2}{*}{ Frequency of Urination } & No & $13(12.6)$ & $90(87.4)$ & 1 & 1 \\
\hline & Yes & $13(21.0)$ & $49(79.0)$ & $1.84(0.79-4.21)^{* *}$ & $0.77(0.23-2.62)$ \\
\hline \multirow{2}{*}{ Urgency } & No & $19(15.3)$ & $105(84.7)$ & 1 & \\
\hline & Yes & $7(17.1)$ & $34(82.9)$ & $1.14(0.44-2.94)$ & \\
\hline \multirow{2}{*}{ History of diabetic } & No & $25(16.1)$ & $130(83.9)$ & 1 & \\
\hline & Yes & $1(10.0)$ & $9(90.0)$ & $0.58(0.07-4.77)$ & \\
\hline \multirow{2}{*}{ History of Catheterization } & No & $24(15.3)$ & $133(84.7)$ & 1 & \\
\hline & Yes & $2(25.0)$ & $6(75.0)$ & $1.85(0.35-9.70)$ & \\
\hline \multirow{2}{*}{ History of UTI } & No & $20(13.9)$ & $124(86.1)$ & 1 & 1 \\
\hline & Yes & $6(28.6)$ & $15(71.4)$ & $2.48(0.86-7.14)^{* *}$ & $2.38(0.73-7.72)$ \\
\hline \multirow{4}{*}{ CD4 values (per $\left.\mathrm{mm}^{3}\right)$} & $>500$ & $7(9.9)$ & $64(90.1)$ & 1 & 1 \\
\hline & $351-500$ & $10(20.8)$ & $38(79.2)$ & $2.41(0.85-6.85)^{* *}$ & $2.23(0.74-6.65)$ \\
\hline & $200-350$ & $4(12.9)$ & $27(87.1)$ & $1.35(0.37-5.01)$ & \\
\hline & $<200$ & $5(33.3)$ & $10(66.7)$ & $4.57(1.21-17.24)^{*}$ & $5.02(1.25-20.15)^{*}$ \\
\hline \multirow{2}{*}{ Symptoms of UTI } & Asymptomatic & $13(13.7)$ & $82(86.3)$ & 1 & \\
\hline & Symptomatic & $13(18.6)$ & $57(81.4)$ & $1.44(0.62-3.33)$ & \\
\hline
\end{tabular}

Where; *p-value $<0.05$ for univariate and multivariate analysis, $* *$ p-value $>0.2$ for univariate analysis only

Of all the bacteria isolated $(\mathrm{n}=26)$, equal proportion of both gram-negative and gram-positive bacteria were found $13(50 \%)$ of each. In addition, figure 1 depicted that among gram negative bacteria the most commonly isolated bacteria were $E$. coli $76.9 \%(10 / 13)$ and the rest was P. mirabilis $23.1 \%(3 / 13)$ and gram positives as follows; S. aureus $61.5 \%(8 / 13), S$. 
saprophyticus $23.1 \%(3 / 13)$ and S. epidermidis $15.4 \%(2 / 13)$ (Figure 1).

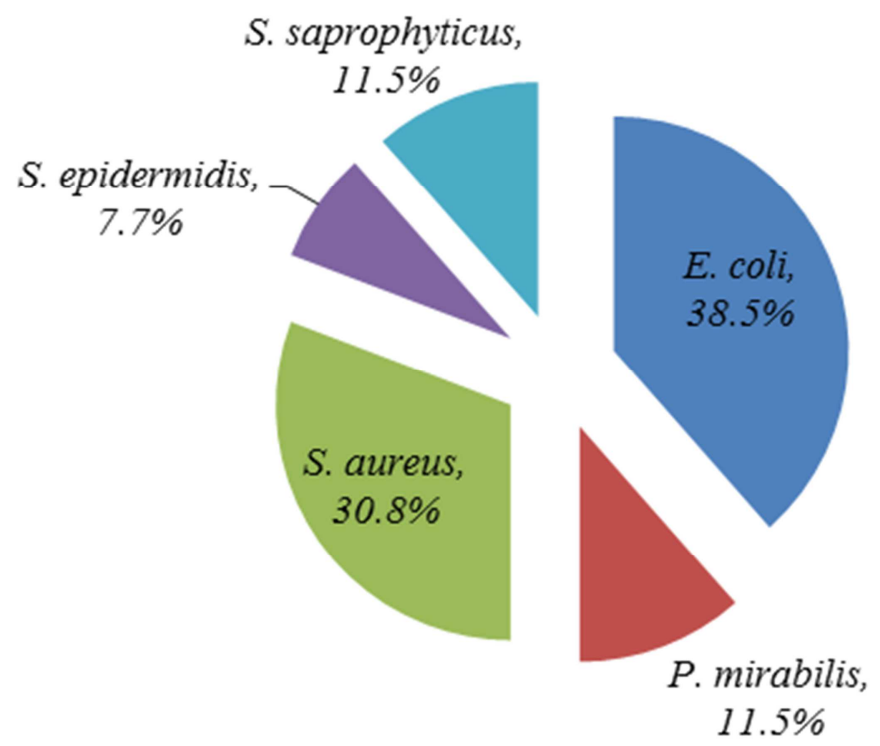

Figure 1. Frequency of bacterial isolates amongst HIV patients in ALERT center; Addis Ababa, Ethiopia; 2015 (n=26).

In regard to drug susceptibility, bacterial isolates in the current study were most sensitive to ceftriaxone (100\%), nitrofurantoin $(88.46 \%)$, gentamicin $(84.62 \%)$ and ceftazidime $(84.62 \%)$ while resistant to ampicillin $(84.62 \%)$, tetracycline $(92.31 \%)$ and trimethoprim-sulfamethoxazole $(88.46 \%)$ as shown in figure 2.

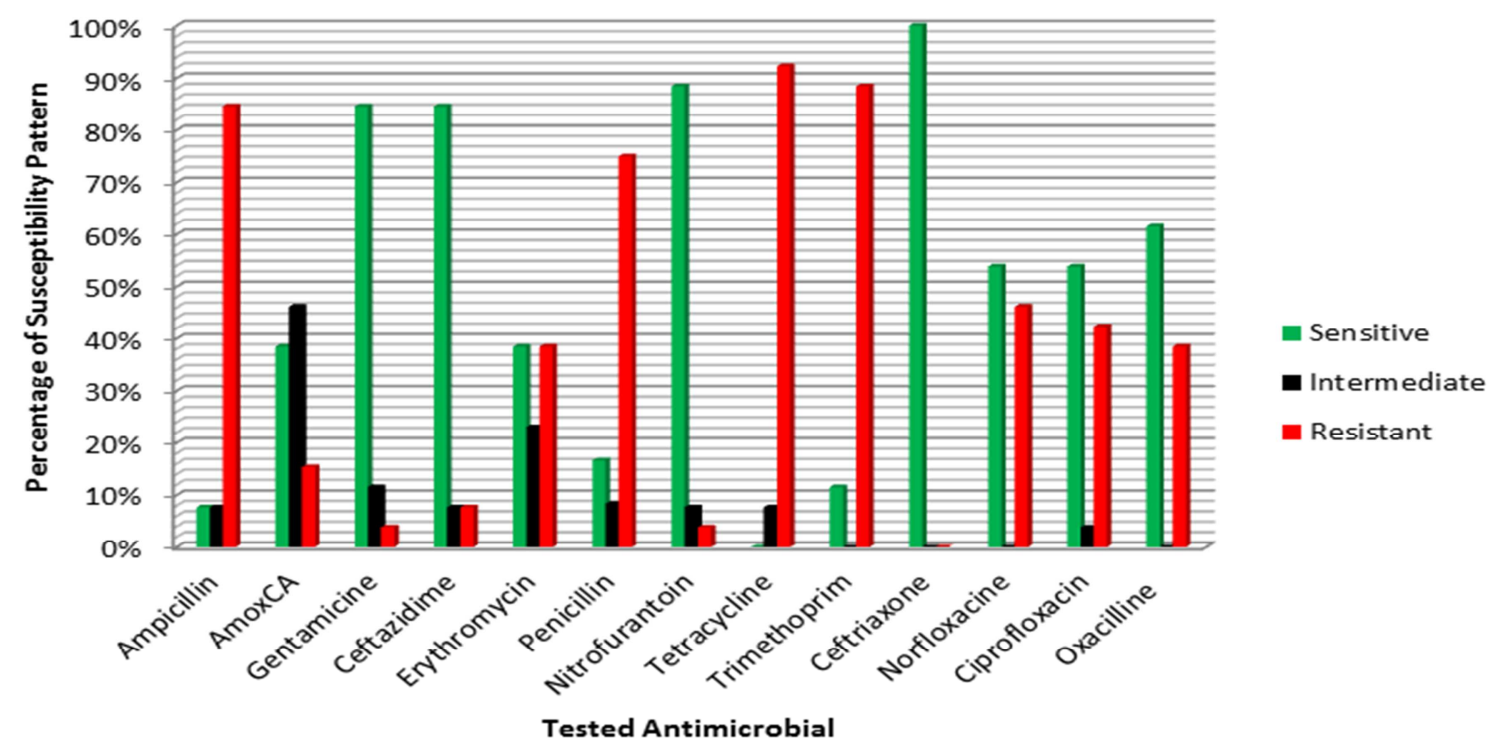

Where; AmoxCA=amoxicillin-clavulanic acid, Trimethoprim= trimethoprim-sulfamethoxazole

Figure 2. Antibiotic susceptibility patterns of bacterial isolates of 26 HIV patients in ALERT center; Addis Ababa, Ethiopia; 2015.

\section{Discussion}

This study aimed to addressing two major issues of clinical significance: prevalence of bacteriuria among HIV positive patients attending ALERT center and to assess antimicrobial susceptibility patterns of the isolated bacteria. The prevalence of bacteriuria in HIV patients of the ALERT center was $15.75 \%$ during the study period. This prevalence found in the range of $10-20 \%$ as reported by others $[10,17,18]$. On the other hand the current prevalence is lower than the findings from Nigeria which is $25.3 \%$ among asymptomatic bacteriuria in patients with antiretroviral drug therapy in Calabar [19] and 23.5\% which aimed to determine the prevalence of urinary tract infections among HIV Patients attending a non- governmental health facility in Jos, Plateau State [20].

In the current study we found that females were tended towards the occurrence of bacteriuria than males. Confirmation from several studies showed that bacteriuria was more common in females than in males [14, 20, 21]. 
Factors such as short urethra and its closeness to the anus as well as sexual activity, decrease of normal vaginal flora, less acidic $\mathrm{pH}$ of vaginal surface, poor hygienic conditions, in general physiological and anatomical differences are accounted for the differences in males and females [20, 21].

This study also revealed that $33.3 \%$ of the study participants with a CD4 count less than 200 per $\mathrm{mm} 3$ had bacteriuria compared with $9.9 \%$ who had CD4 count of greater than 500 cells per $\mathrm{mm} 3$. The current finding was in line with the study done in Nigeria regarding the most affected group in respective study subjects [19]. This could be due to depressed immunity at a declining CD4 counts. We observe that the study subjects who had previous history of UTI and catheterization were more likely susceptible to acquire bacteriuria than who did not have it. This was supported by many other reports in Ethiopia; Gizachew $\mathrm{M}$ et al [22] showed that uropathogen (E. coli) affects those who had previously urinary tract infection respondents of study subjects from Hawassa referral hospital; Alemu A et al [10] also reports that the presence of these conditions also showed high prevalence of bacteriuria in HIV patients. This issue has also been proven in pregnant women [23] and diabetic patients [24].

Indeed, we reported that prevalence of asymptomatic UTI were $57.6 \%(95 / 165)$ out of which in $13.7 \%(13 / 95)$ bacteriuria was detected. The prevalence of bacteriuria we found in asymptomatic UTI study participants was relatively higher than the prevalence in study done by Alemu A et al which aimed to determine the prevalence of uropathogenic bacterial isolates and their antimicrobial susceptibility patterns among HIV/AIDS patients attending Gondar University Specialized Hospital Gondar, Northwest Ethiopia [10]. Whereas, it was lower as compared to study conducted in Nigeria, which revealed the prevalence of $25.3 \%$, from asymptomatic bacteriuria in HIV positive patients [19]. Those findings imply that clinicians should miss some cases of asymptomatic bacteriuria with consequent complications may arising especially in HIV positive patients.

Escherichia coli was the most common uropathogen isolated $(38.5 \%)$. This was supported by many other UTIs studies on HIV positive patients [10,11,20]. This organism also have been identified most frequently in pregnant women [25]. Another study also revealed that E. coli is the predominant pathogenic bacterium among symptomatic outpatient visitors in Gondar, Ethiopia [21]. It is considered the most prominent uropathogenic due to a number of virulence factors specific for colonization and invasion of the urinary epithelium, such as the P-fimbriae and S fimbriae adhesions [25]. However, Ifeanyichukwu et al in Abakaliki, Nigeria found that staphylococcus aureus was the most prevalent organism (45.3\%) isolated from HIV patients [14].

In addition, $S$. aureus, $P$. mirabilis, $S$. saprophyticus and $S$. epidermidis were also isolated as a causative agent of urinary tract infection in HIV patients attending ALERT center during the study period. Moreover, other reports also revealed that these isolates were notoriously identified from HIV positive patients $[10,14,20]$. Indeed, the antimicrobial susceptibility pattern of the isolated uropathogens was investigated.

Therefore, we report that gram negative bacteria (E. coli and $\mathrm{P}$ mirabilis) strains were more susceptible (greater than $80 \%$ ) to gentamicin, ceftazidime, ceftriaxone, norfloxacin and ciprofloxacin. Despite some percentage difference, this was supported by other similar studies on HIV patients which showed gram negative bacteria are more sensitive to these antibiotics [10, 14]. On the other hand these bacteria were more resistant $(66.7 \%-100.0 \%)$ to ampicillin, tetracycline and trimethoprim-sulfamethoxazole. This finding in line with other similar study in Gondar, North-west Ethiopia [10].

Moreover, the current study also revealed that, nitrofurantoin, gentamicin and oxacillin were effective enough against most of the gram positive uropathogen isolates while trimethoprim-sulfamethoxazole, tetracycline, penicillin, norfloxacin and ciprofloxacin were less effective means resistant. Antimicrobial resistance among uropathogens to the commonly used antibiotics is increasing that left clinicians with very few choices of drugs for the treatment of UTI [21]. The antibiotic resistance pattern observed in our study could be due to antibiotic abuse, selfmedication, low cost and availability of these drugs could be contributing factor.

Generally, ceftriaxone, ceftazidime, gentamicin, nitrofurantoin and oxacillin were most effective against the uropthogens isolated in the current study while trimethoprimsulfamethoxazole, tetracycline, ampicillin and penicillin were less effective or resistant. This agrees with the findings of Frank-Peterside et al [7] who reported gentamicin, nitrofurantoin and ceftazidime more effective against most of the urinary isolates of male HIV patients while, ampicillin, penicillin and tetracycline exhibited as resistant. In another study the antibiogram also showed that the antibiotics of choice were gentamicin and nitrofurantoin for the treatment of uropathogens of HIV positive patients [20].

\section{Conclusions}

The prevalence of bacteriuria in our study is found within the range of $10 \%-20 \%$ as reported by other authors in Ethiopia and outside countries. The isolated uropathogens are E. coli, P. mirabilis, $S$. aureus, $S$. saprophyticus and $S$. epidermidis where a predominant of $E$. coli strain. These strains showed different percentage of susceptibility to the tested antibiotic. The current study point out ceftriaxone, ceftazidime, gentamicin and Nitrofurantoin were the choice of drug for the treatment of uropathogens in HIV patients of ALERT Center. Attention should be given for some of the antibiotics of fluoroquinolones category (including ciprofloxacin and norfloxacin) since they are the most commonly prescribed antibiotics for UTI patients. These findings will be important for the management of HIV patients from bacteriuria in the studied area.

\section{Acknowledgement}

We thank Dr Hiwot Mesfin for recruiting the study 
participants. The data collectors and other staff members of the institution involved for their full participation, responsible data collection and support during the study period should also be dully acknowledged. Our gratitude is extended to the study participants for voluntarily participating in this study and for supplying clinical information.

\section{References}

[1] Onyemelukwe NF, Nwokocha ARC. Common Uropathogens That Cause Utis In Enugu Area And Their Sensitivity To Ciprofloxacin. IOSR Journal of Pharmacy and Biological Sciences. 2014; 9(1):77-80.

[2] Ali A, Tayebah V, Farid K, Tayebah A, Farhad A, Marziaeh A. Antimicrobial susceptibility patterns of communityacquired Gram-negative uropathogens. African Journal of Microbiology Research. 2014; 8(4):332-6.

[3] Zareef S, Zafar H, Izhar K, Dodhy ME, Hayat A. The Culture and Sensitivity Pattern of Uropathogens Detected at Benazir Bhutto Hospital. Ann Pak Inst Med Sci. 2009; 5(2):121-5.

[4] Prakash D, Saxena RS. Distribution and Antimicrobial Susceptibility Pattern of Bacterial Pathogens Causing Urinary Tract Infection in Urban Community of Meerut City, India. ISRN Microbiology. 2013; 2013.

[5] Samuel SO, Salami TAT, Adewuyi GM, Babatope E, Ekozien MI. Prevalence of Urinary Tract Infections among a cohort of HIV Positive Patients accessing care in a rural health centre in Nigeria. J Microbiol Biotech Res. 2012; 2(4):507-10.

[6] Olowe OA, Ojo-Johnson BB, Makanjuola OB, Olowe RA, Mabayoje VO. Detection of Bacteriuria Among Human Immunodeficiency Virus Seropositive Individuals in Osogbo, South-west Nigeria. European Journal of Microbiology and Immunology. 2015; 5(1).

[7] Frank-Peterside N, Okerentugba PO, Nwodo CR, Okonko IO. Prevalence of Bacterial Uropathogens in a cohort of HIVPositive Males in Port Harcourt, Nigeria. Cancer Biology. 2013; 3(4):12-7.

[8] Evans JK, McOwan A, Hillman RJ, Forster GE. Incidence of symptomatic urinary tract infections in HIV seropositive patients and the use of co-trimoxazole as prophylaxis against Pneumocystis carznn pneumonia. Genitourin Med. 1995; $71: 120-2$.

[9] Murugesh K, Deepa S, Ravindranath C, Venkatesha D. Multi Drug Resistant Uropathogens in HIV: Are They A Threat to Community? International Journal of Scientific Study. 2014; 2(3):38-42.

[10] Alemu A, Dagnew M, Alem M, Gizachew M. Uropathogenic Bacterial Isolates and their Antimicrobial Susceptibility Patterns among HIV/AIDS Patients Attending Gondar University Specialized Hospital Gondar, Northwest Ethiopia. Journal of Microbiology Research and Reviews. 2013 1(4):42-51.

[11] Akinbami A, Bode-Shojobi I, Ajibola S, Oshinaike O, Adediran A, Ojelabi O, et al. Prevalence of Asymptomatic Bacteriuria in HIV Infected Patients in a Tertiary Hospital in Lagos, Nigeria. World Journal of AIDS. 2013; 3:105-10.

[12] Mwaka AD, Mayanja-Kizza H, Kigonya E, Kaddu-Mulindwa D. Bacteriuria among adult non-pregnant women attending
Mulago hospital assessment centre in Uganda. African Health Sciences. 2011; 11(2):182 - 9 .

[13] Aminu KY, Aliyu UU. Asymptomatic Bacteriuria in Pregnant Women in the Antenatal Booking Clinic at Aminu Kano Teaching Hospital, Kano, Nigeria. Open Journal of Obstetrics and Gynecology. 2015; 5:286-97.

[14] Ifeanyichukwu I, Emmanuel N, Chika E, Anthonia O, Esther U, Ngozi A, et al. Frequency and Antibiogram of uropathogens isolated from Urine Samples of HIV Infected Patients on Antiretroviral Therapy. American Journal of BioScience. 2013; 1(3):50-3.

[15] Cheesbrough M. District Laboratory Practice in Tropical Countries (part 2). 2nd ed. New York: Cambridge University Press; 2006. 54-9 p.

[16] CLSI. Performance Standards for Antimicrobial Disk Susceptibility Tests; Approved Standard-Eleventh Edition. CLSI document M02-A11. Wayne, PA: Clinical and Laboratory Standards Institute; 2012.

[17] Iduoriyekemwen NJ, Sadoh WE, Sadoh AE. Asymptomatic Bacteriuria in HIV Positive Nigerian Children. Journal of Medicine and Biomedical Research. 2012; 11(1):88-94.

[18] Debalke S, Cheneke W, Tassew H, Awol M. Urinary Tract Infection among Antiretroviral Therapy Users and Nonusers in Jimma University Specialized Hospital, Jimma, Ethiopia. International Journal of Microbiology. 2014; 2014.

[19] Inayg-Etoh PC, Udofia GC, Alaribe AA, Udonwa NE. Asymptomatic bacteriuria on patients on antiretroviral drug therapy in Calabar. Journal of medical science. 2009; 9(6):270-5.

[20] Bigwan EI, Wakjissa FD. Prevalence of Urinary Tract Infections among HIV Patients Attending a NonGovernmental Health Facility in Jos, Plateau State, Nigeria. International Journal of Biomedical and Advance Research. 2013; 4(8).

[21] Alemu A, Unakal C. Prevalence and antimicrobial susceptibility pattern of urinary tract infection causing human pathogenic bacteria among symptomatic outpatients visiting Gondar University hospital Gondar, Northwest Ethiopia. Novus International Journal of Medical Science. 2013; 2(2).

[22] Gizachew M, Kebede M, Merid Y, Sinshaw Y, Tiruneh M, Alemayehu M, et al. Escherichia coli isolated from patients suspected for urinary tract infections in Hawassa Referral Hospital, Southern Ethiopia: An institution based cross sectional study. Journal of Microbiology Research and Reviews. 2013; 1(1):009-15.

[23] Haider G, Zehra N, Munir AA, Haider A. Risk factors of urinary tract infection in pregnancy. J Pak Med Assoc. 2010; 60(3).

[24] Gizachew Y, Daniel A, Yimtubezinash W, Chandrashekhar GU. Urinary Tract Infection: Bacterial etiologies, drug resistance profile and associated risk factors in diabetic patients attending Gondar University Hospital, Gondar, Ethiopia. European Journal of Experimental Biology. 2012; 2(4):889-98.

[25] Alemu A, Moges F, Shiferaw Y, Tafess K, Kassu A, Anagaw $\mathrm{B}$, et al. Bacterial profile and drug susceptibility pattern of urinary tract infection in pregnant women at University of Gondar Teaching Hospital, Northwest Ethiopia. BMC Research Notes. 2012; 5(197). 